\title{
Prevalence of monarch (Danaus plexippus) and queen (Danaus gilippus) butterflies in West Texas during the fall of 2018
}

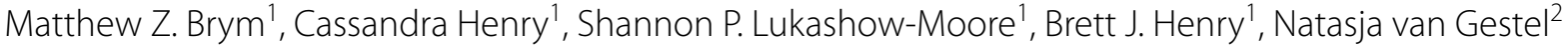 \\ and Ronald J. Kendall ${ }^{1 *}$ (D)
}

\begin{abstract}
Background: The monarch butterfly (Danaus plexippus) is a conspicuous insect that has experienced a drastic population decline over the past two decades. While there are several factors contributing to dwindling monarch populations, habitat loss is considered the most significant threat to monarchs. In the United States, loss of milkweed, particularly in the Midwest, has greatly reduced the available breeding habitat of monarchs. This has led to extensive efforts to conserve and restore milkweed resources throughout the Midwest. Recently, these research and conservation efforts have been expanded to include other important areas along the monarch's migratory path.
\end{abstract}

Results: During the fall of 2018, we conducted surveys of monarch eggs and larvae through West Texas. We documented monarch and queen butterfly (Danaus gilippus) reproduction throughout the region and used the proportion of monarch and queen larva to estimate the number of monarch eggs. Peak egg densities for monarchs were as high as 0.78 per milkweed ramet after correction for the presence of queens. Despite our observations encompassing only a limited sample across one season, the peak monarch egg densities we observed exceeded published reports from when monarch populations were higher.

Conclusions: To our knowledge, this is the first study to correct for the presence of queens when calculating the density of monarch eggs. This research also provides insight into monarch utilization of less well-known regions, such as West Texas, and highlights the need to expand the scope of monarch monitoring and conservation initiatives. While the importance of monarch research and conservation in the Midwest is unquestionable, more comprehensive efforts may identify new priorities in monarch conservation and lead to a more robust and effective overall strategy, particularly given the dynamic and rapidly changing global environment.

Keywords: Monarch butterfly, Danaus plexipuus, West Texas, Migration, Reproduction, Egg correction

\section{Background}

Monarch butterflies (Danaus plexippus) are perhaps the most widely known and recognizable of all insects. These butterflies are a classic example of plant-insect interactions, mimicry, and aposematic coloration [1]. Monarchs

*Correspondence: Ron.Kendall@ttu.edu

${ }^{1}$ The Wildlife Toxicology Laboratory, Texas Tech University, Box 43290, Lubbock, TX 79409-3290, USA

Full list of author information is available at the end of the article are best known, however, for the bi-annual migration of the eastern population between overwintering grounds in central Mexico and summer breeding areas that span from northern Mexico to southern Canada [7, 54]. Monarchs are also well known in the western United States (US), as this area harbors a distinct population that exhibits a similar, albeit less extensive, migration within the region [16]. Unfortunately, the monarch migration is imperiled, both east and west of the Rocky Mountains, 
due to steep declines in monarch abundance over the past several decades $[9,48]$.

Since the 1990s, the eastern population of monarchs is estimated to have decreased by $80 \%$ [49], while its western counterpart has declined by over $99 \%$ since the 1980 s [36]. The threats to monarchs are varied and range from extreme weather events [12] and parasites $[2,6]$ to predation by invasive pests [13] and numerous insect taxa [23]. While many of these factors present substantial threats to monarchs, habitat loss may be the most damaging to overall monarch numbers given the restricted distribution of their overwintering habitat and specialized larval diet [29]. The loss of breeding habitat, in particular, is well supported as a primary cause of monarch declines [52].

In the US, changing agricultural practices and increased herbicide use have led to widespread losses of milkweeds (Asclepias spp.), which are an essential food source for monarch larva [39]. Milkweeds in the Midwestern US are considered especially important, as this area has been documented as the primary repopulation zone for monarchs [55]. Because of the monarchs reliance on milkweed, safeguarding and restoring these plants is a top priority for monarch conservation, and it is estimated that $\sim 1.6$ billion milkweeds must be added to the Midwest in order to reach conservation goals set by the Pollinator Health Task Force [40]. More recently, researchers have also stressed the necessity to expand monarch conservation initiatives beyond the Midwest, as other regions, like the southern US, have been identified as key natal areas for butterflies that go on to colonize summer breeding grounds [18].

Considering the wide spatiotemporal distribution of monarchs, broadening conservation efforts may allow for greater protection of important habitat, offer more area for restoration initiatives, and increase resilience to localized calamities and stochastic variability. A broader focus could also help to distribute the costs associated with monarch conservation across a wider base, allowing for the mobilization of more resources towards milkweed propagation and restoration, habitat conservation, monarch monitoring, etc. Indeed, while the southern and north central portions of the monarchs breeding range are regarded as a priority, there is also agreement that an investment in conservation efforts across the entirety of the monarch's migratory distribution would likely yield the most effective strategy to mitigate monarch declines $[19,20,34]$.

However, despite the potential benefits of a comprehensive strategy for monarch conservation, there are also obstacles which impede the implementation of such an approach. For example, there are over 130 species of milkweeds growing across North America [17, 58], and these may require different cultivation techniques and growing conditions [27]. Milkweed may also be unavailable commercially, making large scale conservation and restoration initiatives difficult in areas where local plant ecotypes are scarce [5]. Determining what species of milkweeds to select and how to distribute them also presents a challenge, as studies show that monarch utilization is affected by site and landscape characteristics [22, $38,62]$, ovipositing females prefer some milkweed species over others $[3,25,42,43]$, and larval success varies with milkweed species as well $[25,41,60]$.

Ultimately, a significant barrier to more widespread monarch conservation is an incomplete understanding of the factors affecting monarch success and habitat utilization. Addressing this requires comprehensive monitoring, and while much effort has been focused on the Midwest [53], research into other areas along the monarch's migratory route is more limited. The limitations within the knowledge base are present even in areas considered to be highly significant to monarch conservation, like Texas. Although Texas has several monarch monitoring programs such as Texas Monarch Watch [44], growing coverage due to citizen science programs [24], and surveys by Calvert and Wagner [14], there are still gaps in our understanding of how monarchs utilize resources within the state. This is especially true for the western portion of the state, which is sparsely populated and oftentimes overlooked in comparison to the rest of Texas [10]. However, recent surges in monarch abundance through West Texas may offer insight into the significance of this region that warrants further investigation. In this study, we examine surveys of monarch egg and larval abundance from West Texas during the fall of 2018. If monarch abundance in West Texas is comparable to that of more widely recognized and monitored regions, it may be worthwhile to look more closely at the significance of this area in terms of monarch conservation.

\section{Results \\ Proportion of eggs based on larva}

The proportion of monarch larva observed was consistently higher than that of queen butterfly (Danaus gilippus) larva across the majority of our study sites and survey sessions (Table 1 ). There were only 6 of the 48 surveys where queen larva exceeded that of monarchs, and these only occurred on 2 of the sites. During September 30th, an equal number of monarch and queen larva were observed at Stonewall 3, and this was also the case at both Fisher 1 and Stonewall 2 on October 22nd. The number of monarch and queen eggs based on these proportions and confidence intervals is summarized in Table 2. It is important to note that estimating the number of monarch eggs by multiplying total eggs observed 
Table 1 Summary of monarch and queen proportions

\begin{tabular}{|c|c|c|c|c|c|c|c|c|c|c|c|c|c|}
\hline \multirow[t]{2}{*}{ Date } & \multirow[t]{2}{*}{ Species } & \multicolumn{2}{|c|}{ Fisher 1} & \multicolumn{2}{|c|}{ Fisher 2} & \multicolumn{2}{|c|}{ Fisher 3} & \multicolumn{2}{|c|}{ Stonewall 1} & \multicolumn{2}{|c|}{ Stonewall 2} & \multicolumn{2}{|c|}{ Stonewall 3} \\
\hline & & $P$ & $\mathrm{Cl}$ & $\mathbf{P}$ & $\mathrm{Cl}$ & $P$ & $\mathrm{Cl}$ & $P$ & $\mathrm{Cl}$ & $P$ & $\mathrm{Cl}$ & $P$ & $\mathrm{Cl}$ \\
\hline \multirow[t]{2}{*}{$9 / 14 / 18$} & M & 0.86 & $0.74-0.97$ & 0.75 & $0.59-0.91$ & 0.90 & $0.71-1.09$ & 1.00 & NA & 0.64 & $0.35-0.92$ & 1.00 & NA \\
\hline & Q & 0.14 & $0.03-0.26$ & 0.25 & $0.09-0.41$ & 0.10 & $-0.09-0.29$ & 0 & NA & 0.36 & $0.08-0.65$ & 0 & NA \\
\hline \multirow[t]{2}{*}{$9 / 24 / 18$} & M & 0.62 & $0.44-0.80$ & 0.95 & $0.89-1.02$ & 0.81 & $0.66-0.96$ & 1.00 & NA & 0.39 & $0.19-0.59$ & 0.83 & 0.54 \\
\hline & Q & 0.38 & $0.20-0.56$ & 0.05 & $-0.02-0.11$ & 0.19 & $0.04-0.34$ & 0 & NA & 0.61 & $0.41--0.81$ & 0.17 & $-0.13-0.46$ \\
\hline \multirow[t]{2}{*}{$9 / 30 / 18$} & M & 1.00 & NA & 0.81 & $0.64-0.98$ & 0.88 & $0.71-1.04$ & 1.00 & NA & 0.36 & $0.08-0.65$ & 0.50 & $-0.19-1.19$ \\
\hline & Q & 0 & NA & 0.19 & $0.02-0.36$ & 0.13 & $-0.04-0.29$ & 0 & NA & 0.64 & $0.35-0.92$ & 0.50 & $-0.19-1.19$ \\
\hline \multirow[t]{2}{*}{$10 / 5 / 18$} & M & 0.90 & $0.71-1.09$ & 0.73 & $0.51-0.96$ & 0.65 & $0.42-0.87$ & 1.00 & NA & 0.44 & $0.19-0.68$ & 0 & NA \\
\hline & Q & 0.10 & $-0.09-0.29$ & 0.27 & $0.04-0.49$ & 0.35 & $0.13-0.58$ & 0 & NA & 0.56 & $0.32-0.81$ & 1.00 & NA \\
\hline \multirow[t]{2}{*}{ 10/12/18 } & M & 0.86 & $0.60-1.12$ & 0.77 & $0.54-1.00$ & 0.60 & $0.17-1.03$ & NLO & NA & 0.71 & $0.38-1.05$ & 0.17 & $-0.13-0.46$ \\
\hline & Q & 0.14 & $-0.12-0.40$ & 0.23 & $0-0.46$ & 0.40 & $-0.03-0.83$ & NLO & NA & 0.29 & $-0.05-0.62$ & 0.83 & $0.54-1.13$ \\
\hline \multirow[t]{2}{*}{$10 / 22 / 18$} & M & 1.00 & NA & 0.67 & $0.13-1.20$ & 0.50 & $-0.19-1.19$ & 1.00 & NA & 0.50 & $0.15-0.85$ & 0 & NA \\
\hline & Q & 0 & NA & 0.33 & $-0.20-0.87$ & 0.50 & $-0.19-1.19$ & 0 & NA & 0.50 & $0.15-0.85$ & 1.00 & NA \\
\hline \multirow[t]{2}{*}{ 10/29/18 } & M & 1.00 & NA & 1.00 & NA & 1.00 & NA & NLO & NA & 0.60 & $0.17-1.03$ & NLO & NA \\
\hline & Q & 0 & NA & 0 & NA & 0 & NA & NLO & NA & 0.40 & $-0.03-0.83$ & NLO & NA \\
\hline \multirow[t]{2}{*}{$11 / 9 / 18$} & M & NLO & NA & NLO & NA & NLO & NA & NLO & NA & 1.00 & NA & NLO & NA \\
\hline & $\mathrm{Q}$ & NLO & NA & NLO & NA & NLO & NA & NLO & NA & 0 & NA & NLO & NA \\
\hline
\end{tabular}

Proportions $(\mathrm{P})$ of monarch $(\mathrm{M})$ and queen $(\mathrm{Q})$ butterfly larvae with $95 \%$ confidence intervals $(\mathrm{Cl})$ by date and site. Confidence intervals were not available (NA) when there were either no larvae observed (NLO) or there was only one species of larvae observed

by the proportion of monarch to queen larva does not consider factors such as differing egg and larval survival rates between the two butterfly species. However, because we found no published comparisons of survival rates between immature queen and monarch butterflies, and rearing eggs for positive identification was beyond the scope of this study, we were unable to more precisely estimate the number of monarch eggs observed. Nevertheless, the close relationship and similar life histories of the two butterflies suggest that our estimates of monarch eggs were generally representative. This is supported by a study that found the immature survival rates of monarchs and another congeneric species, the African queen (Danaus chrysippus), to be similar [59].

\section{Comparison of abundance}

Across the two counties, monarch egg and larva abundance generally followed a downward trend, with a few exceptions that can be visualized in Fig. 1. Monarch eggs and larva were also more abundant in Fisher County overall. In contrast, queen eggs and larva were most abundant at Stonewall 2 but appeared to be more evenly distributed throughout the Fisher County sites (Fig. 2). As the sampling period progressed, there were fewer plants sampled with a higher proportion of senescing plants (Fig. 3).

Peak abundance and maximum average density of monarch eggs occurred during the first survey on September 14th when a total of 235 Danaus eggs were

Table 2 Summary of estimated monarch and queen eggs

\begin{tabular}{|c|c|c|c|c|c|c|c|c|c|c|c|c|c|c|c|c|c|c|}
\hline \multirow[t]{2}{*}{ Date } & \multicolumn{3}{|c|}{ Fisher 1} & \multicolumn{3}{|c|}{ Fisher 2} & \multicolumn{3}{|c|}{ Fisher 3} & \multicolumn{3}{|c|}{ Stonewall 1} & \multicolumn{3}{|c|}{ Stonewall 2} & \multicolumn{3}{|c|}{ Stonewall 3} \\
\hline & $M$ & $\mathbf{Q}$ & \pm & $M$ & $\mathbf{Q}$ & \pm & $M$ & $\mathrm{Q}$ & \pm & $M$ & $\mathbf{Q}$ & \pm & $\mathrm{M}$ & $\mathbf{Q}$ & \pm & $M$ & $\mathbf{Q}$ & \pm \\
\hline $9 / 14 / 18$ & 25 & 15 & 7 & 92 & 5 & 6 & 54 & 13 & 10 & 20 & 0 & NA & 2 & 2 & 1 & 6 & 1 & 2 \\
\hline $9 / 24 / 18$ & 7 & 0 & NA & 9 & 2 & 2 & 9 & 1 & 2 & 7 & 0 & NA & 10 & 18 & 8 & 1 & 1 & 1 \\
\hline $9 / 30 / 18$ & 33 & 4 & 7 & 12 & 4 & 4 & 8 & 4 & 3 & 8 & 0 & NA & 5 & 6 & 3 & 0 & 5 & NA \\
\hline $10 / 5 / 18$ & 5 & 1 & 2 & 1 & 0 & NA & 2 & 2 & 2 & 0 & 0 & NA & 3 & 1 & 1 & 1 & 3 & 1 \\
\hline $10 / 12 / 18$ & 0 & 0 & NA & 0 & 0 & NA & 0 & 0 & NA & 0 & 0 & NA & 0 & 0 & NA & 0 & 0 & NA \\
\hline $10 / 22 / 18$ & 2 & 0 & NA & 0 & 0 & NA & 0 & 0 & NA & 0 & 0 & NA & 11 & 8 & 8 & 0 & 0 & NA \\
\hline $10 / 29 / 18$ & 0 & 0 & NA & 0 & 0 & NA & 0 & 0 & NA & 0 & 0 & NA & 6 & 0 & NA & 0 & 0 & NA \\
\hline
\end{tabular}

Estimated number of monarch $(\mathrm{M})$ and queen $(\mathrm{Q})$ eggs based on the subsequent weeks proportion of larvae with \pm representing the calculated confidence interval for the proportions by date and site. Confidence intervals were not available for all proportions and this is represented by NA 


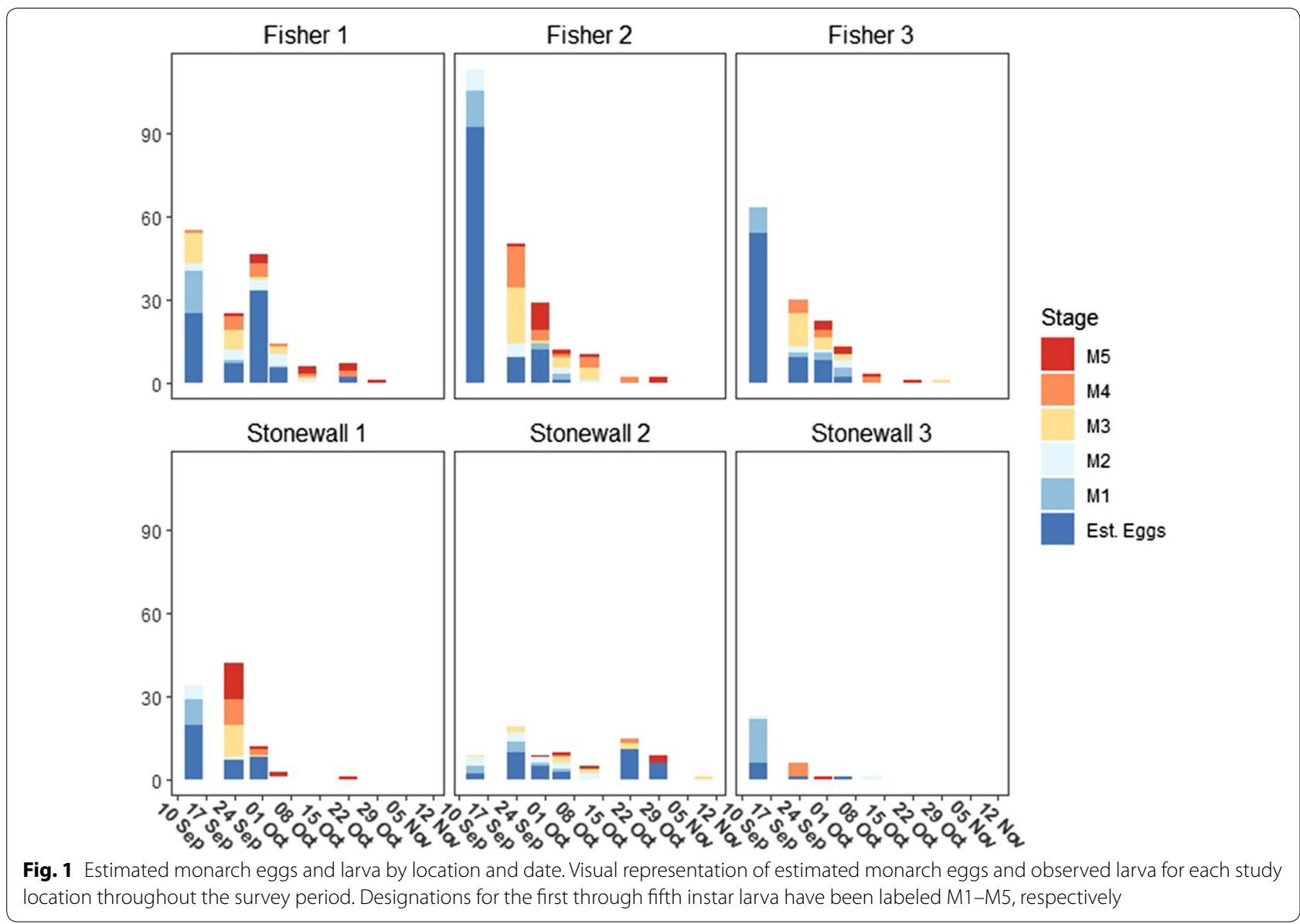

counted across 6 sites and $\sim 240$ milkweed ramets (Table 3). After correcting for the number of queen eggs, we estimated $\sim 187$ monarch eggs were observed during this session resulting in an overall density of $\sim 0.78$ monarch eggs per milkweed ramet. Over the course of the study period, 1307 milkweed ramets were surveyed for monarchs across 6 sites and 8 monitoring sessions. The number of milkweed ramets examined averaged $163 \pm 57$ per session and ranged from a maximum of 245 on September 24th to a minimum of 83 on November 9th. The best supported model of the candidate models for estimated monarch egg density included only Julian date (Table 4), with egg density decreasing over time across both Fisher $(\mathrm{p}<0.0001)$ and Stonewall $(\mathrm{p}=0.0044)$ counties (Fig. 4). This model was chosen because it had the lowest $\mathrm{AIC}_{\mathrm{c}}$ and a $w_{\mathrm{i}}$ of 0.768 . Because the second-best model had a $\Delta_{i}$ of 3.01 , we did not use model averaging.

\section{Discussion}

With the increased attention and effort given to the protection of monarchs, as well as emphasis towards conservation initiatives across a wider portion of their migratory range $[19,20,34]$, it is necessary to enhance our understanding of the phenology and migratory dynamics of this butterfly. This is particularly important given the threat of climate change and its potential to affect the abundance, distributions, and habitats of migratory organisms [46] like the monarch [26]. In this study, we observed substantial utilization of milkweed resources and reproduction of monarchs, with all larval stages documented in West Texas during the fall of 2018. This coincided with a surge of citizen scientist reports of monarchs following a more westerly distribution, with concentrations of butterflies being found as far west as Colorado and New Mexico [24]. Although West Texas has limited monarch monitoring initiatives on account of its sparse population and location at the edge of the migratory corridor [10], our results suggest 


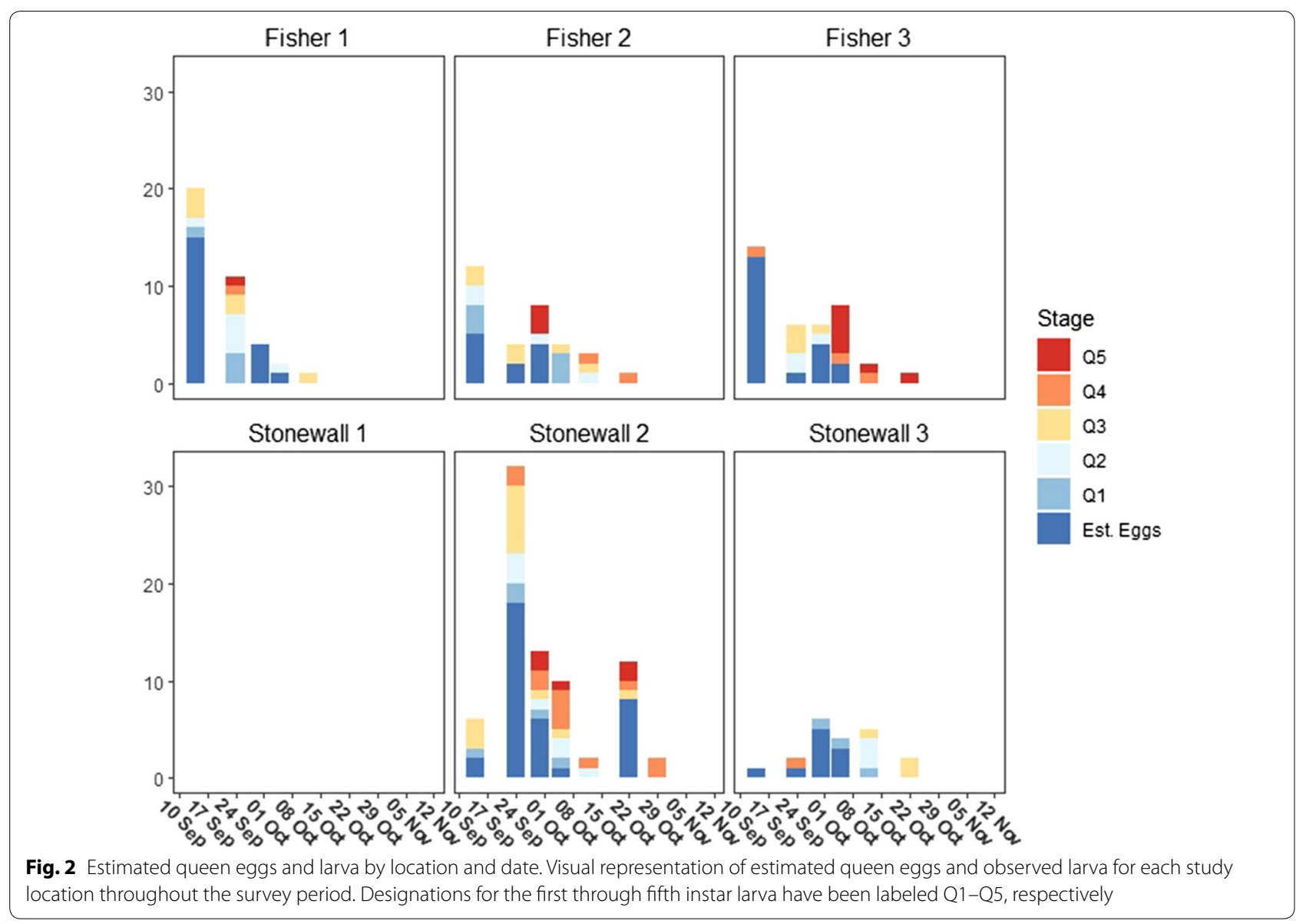

that further examination of monarch utilization in this area may be warranted.

This assessment of monarch activity in West Texas also provides a preliminary account of how monarchs utilize milkweed resources within the region during the fall. We noted a high degree of variability in monarch utilization between sites which was consistent with that of other studies [22, 38, 51]. We also noted a potential difference in the utilization of milkweed species between queen and monarch butterflies, as queens were disproportionately distributed at Stonewall 2. The disproportion of queens may be due to this site being the only one that contained zizotes milkweed (Asclepias oenotheroides). Although one site with zizotes is insufficient to evaluate the preference of milkweed species by monarchs and queens in Texas, it does highlight the need to further study this dynamic. Additionally, the differences between study locations during different sampling periods emphasize the need to account for the proportion of queen eggs when calculating monarch egg densities, which are a standard for assessing the utilization of milkweed resources in an area. If queen eggs are not accounted for, there is the potential for this to significantly affect estimates of monarch utilization in areas, like Texas, where the two species are sympatric.

Because monarchs are influenced by the availably of milkweed and flowering plants along their migratory routes, dynamic weather patterns that shift the distribution of these resources may likewise affect their migration $[4,26,61]$. Models also suggest that the distributions of both monarchs and milkweed are limited by precipitation and temperature, with the distribution of milkweed being a strong predictor of monarch observations [26]. The successive northward expansion of monarchs during the spring is an example of the coadaptation of monarchs and milkweed to avoid increasing temperatures and deteriorating milkweed resources in southern areas [30]. Given the delayed and more gradual onset of winter in the US due to climate change [37], it may also be pertinent to consider the possibility of similar southward movement that precedes the main migration of reproductively inactive adults. This is intriguing, as the peak abundance of monarch eggs we observed on September 14th preceded the height of the monarch migration through our study area, which occurred on October 10th 


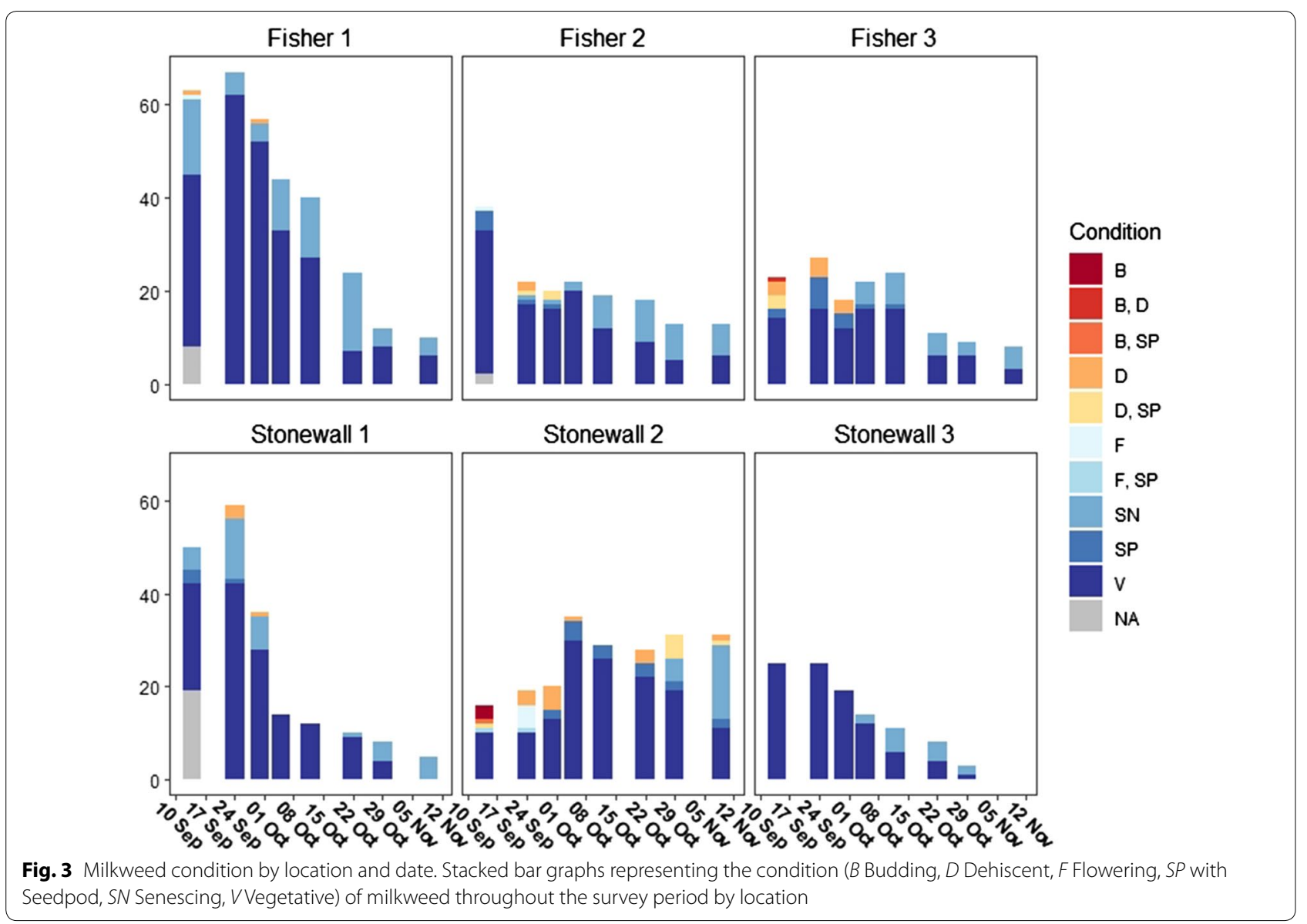

Table 3 Summary of monarch egg and larva surveys

\begin{tabular}{lccl}
\hline Date & $\begin{array}{l}\text { Milkweed } \\
\text { ramets } \\
\text { surveyed }\end{array}$ & $\begin{array}{l}\text { Total estimated } \\
\text { monarch eggs }\end{array}$ & $\begin{array}{l}\text { Estimated } \\
\text { monarch eggs } \\
\text { per ramet }\end{array}$ \\
\hline $9 / 14 / 2018$ & 240 & 187 & 0.78 \\
$9 / 24 / 2018$ & 245 & 51 & 0.21 \\
$9 / 30 / 2018$ & 189 & 59 & 0.31 \\
$10 / 5 / 2018$ & 176 & 13 & 0.07 \\
$10 / 12 / 2018$ & 151 & 0 & 0 \\
$10 / 22 / 2018$ & 122 & 16 & 0.13 \\
$10 / 29 / 2018$ & 101 & 6 & 0.06 \\
$11 / 9 / 2018$ & 83 & 0 & 0 \\
Total & 1307 & 332 & 0.25 \\
\hline
\end{tabular}

Average number of milkweed ramets surveyed and monarchs observed per milkweed ramet over 8 weekly sessions in West Texas during the fall of 2018

[24]. The following survey on September 24th yielded the highest number of monarch larva counted during the study, suggesting that conditions were favorable for egg hatching and larval development. Overall milkweed quality and the total number of ramets observed was also the highest during this time, potentially due to increased precipitation in West Texas during the early autumn of 2018 [32]. Thus, the monarch breeding we observed may have been a response to plentiful milkweed resources promoted by increased precipitation in West Texas, and further research may provide insight into the importance of such opportunities, as well as the ability of monarchs to find and exploit them.

Increasing regional temperatures [31] may have further contributed to the amount of monarch breeding we observed. Temperature is an important cue governing reproductive diapause in monarchs [21] and higher temperatures could have broken diapause in migrants from further north and/or delayed the onset of diapause in butterflies with more southerly origins. The potential of increased temperature to extend the period of monarch reproductive activity has been highlighted before [21, 26], and this may explain our observations of additional, albeit smaller, peaks in monarch reproduction into October, during which we would expect monarchs to be in diapause.

While assessing the impacts of phenological shifts of host plants and climate change on monarchs was beyond the scope of this study, our observations emphasize the 
Table 4 Summary of candidate models

\begin{tabular}{|c|c|c|c|c|c|c|}
\hline Candidate model & Fixed effects of candidate models & $D f$ & $\mathrm{AIC}_{\mathrm{c}}$ & $\Delta i$ & $W_{\mathrm{i}}$ & $E_{\mathrm{i}}$ \\
\hline Model 1 & Julian day & 7 & 187.56 & 0 & 0.768 & 1 \\
\hline Model 2 & Julian day + Plot area & 9 & 190.58 & 3.01 & 0.170 & 5 \\
\hline Model 3 & Julian day + Area size & 9 & 194.24 & 6.68 & 0.027 & 28 \\
\hline Model 4 & Julian day + Ramet density & 9 & 194.39 & 6.83 & 0.025 & 30 \\
\hline Model 5 & Julian day + Ramet density + Plot area & 11 & 197.31 & 9.75 & 0.006 & 131 \\
\hline Model 6 & Julian day + Area size + Plot area & 11 & 198.57 & 11.01 & 0.003 & 246 \\
\hline Model 7 & Julian day + Ramet density + Area size & 11 & 201.78 & 14.22 & 0.001 & 1222 \\
\hline Model 8 & Julian day + Ramet density + Area size + Plot area & 13 & 206.80 & 19.24 & 0 & 15,035 \\
\hline Model 9 & Area size & 5 & 220.49 & 32.92 & 0 & $>10^{6}$ \\
\hline Model 10 & Plot area & 5 & 221.03 & 33.47 & 0 & $>10^{6}$ \\
\hline Model 11 & Area size + Plot area & 9 & 225.76 & 38.20 & 0 & $>10^{7}$ \\
\hline Model 12 & Ramet density + Area size + Plot area & 7 & 226.80 & 39.24 & 0 & $>10^{7}$ \\
\hline Model 13 & Ramet density & 5 & 227.07 & 39.51 & 0 & $>10^{7}$ \\
\hline Model 14 & Ramet density + Area size & 7 & 233.97 & 46.41 & 0 & $>10^{9}$ \\
\hline Model 15 & Ramet density + Plot area & 7 & 234.87 & 47.31 & 0 & $>10^{9}$ \\
\hline
\end{tabular}

The set of candidate models used in the model selection procedure to predict monarch egg density (eggs/milkweed ramet). All candidate models are generalized additive mixed models with site (Fisher 1-3 and Stonewall 1-3) as the random intercept. Our predictor variables were Julian day, plot area, area size, and ramet density (ramets $/ \mathrm{m}^{2}$ ). We considered all possible combinations of these predictor variables. Smoothers were applied to Julian day (at the county level), plot size, and ramet density. The results are based on a negative binomial distribution because of overdispersion. Results presented include the degrees of freedom (df), corrected AIC $\left(A I C_{c}\right)$, the $A_{C} C_{c}$ difference between the best model and all other models $(\Delta i)$, Akaike weights $\left(w_{i}\right)$, and the evidence ratio $\left(E_{j}\right)$. The results are ranked by $A I C_{c}$, from the best to the worst model

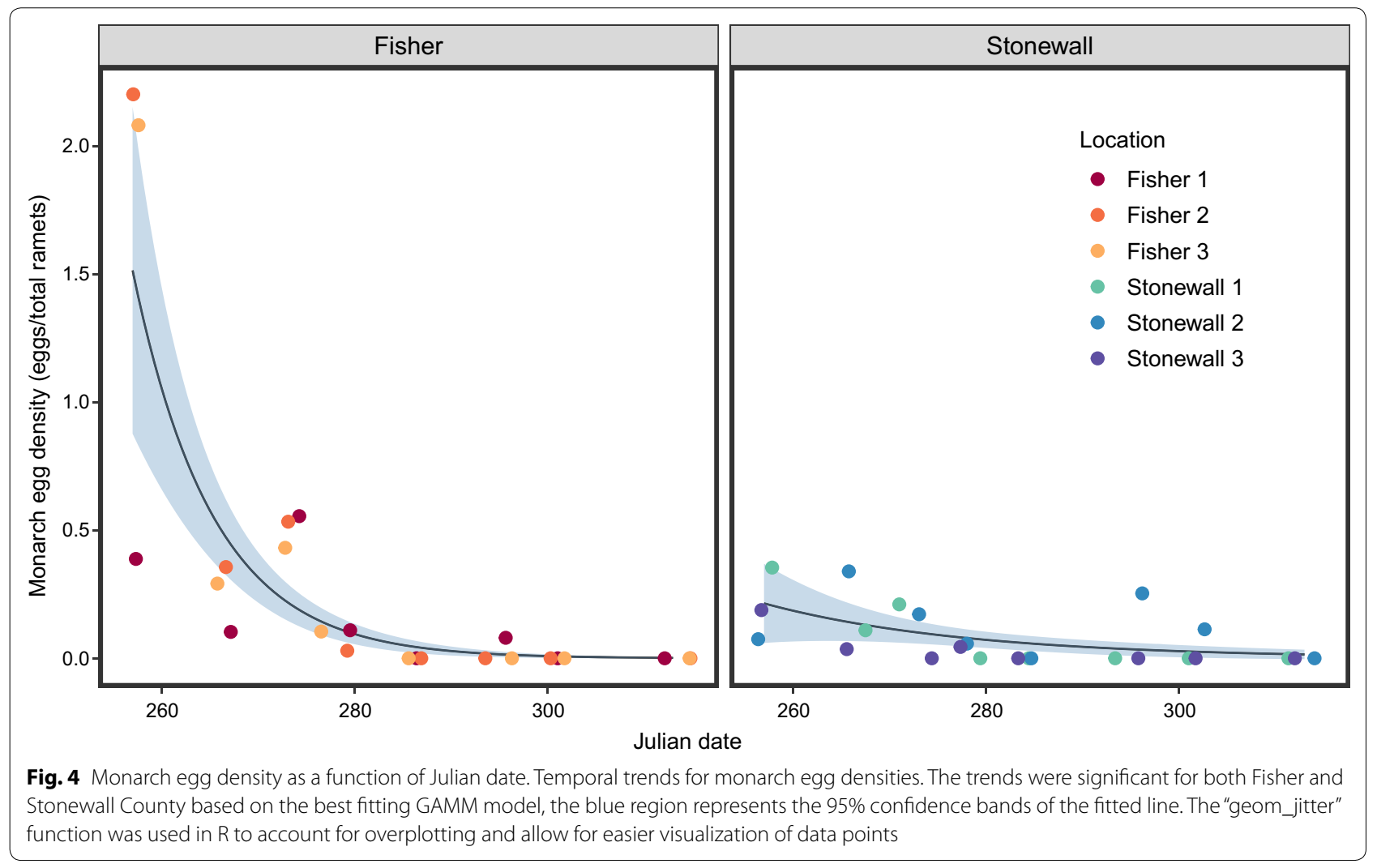


need to further investigate these dynamics, as they may have profound effects on the monarch's migratory cycle. Such climatic variability could positively impact monarchs as increased abundance of host plants and higher fall temperatures along the southern extent of the monarch's migratory range may allow for an additional generation, thereby causing this region to serve as a source for monarch populations. Conversely, if monarchs along their southward migration are reproductively active but there is not enough time for their offspring to mature before the onset of winter and adults expend energy essential for overwintering on breeding, the southern portion of the monarch's migratory range would act as an ecological trap for the butterflies.

Continued monitoring of monarchs in West Texas is therefore necessary to develop our understanding of how monarchs utilize resources within this region, as well as provide greater insight into this particular stage of the monarch's migration. These efforts may also allow us to better assess the significance of the western extent of the monarch's migratory corridor compared to other areas. During the peak of monarch activity in our study area, we documented an average of 0.78 monarch eggs per milkweed ramet. This was higher than reported by Stenoien et al. [51] during 14 of their 17 years assessing fall monarch egg densities in the southcentral US, which included sites from central and eastern Texas but lacked any in West Texas. Additionally, the densities reported here were higher than 8 of 14 years of spring densities in the southcentral US, 17 of 18 years of spring densities in the northcentral US, and all 18 years of summer densities in the northcentral US [51]. However, monarch egg densities from the southcentral US, in particular, were subject to a wide degree of variance [51], and because our sample was relatively small and limited to only 1 year, the higher egg densities we observed may have been due to stochastic variability.

The comparison between our data set and Stenoien et al. [51] is further limited as the latter was taken years before our study and encompassed different phases of the monarch's migratory cycle. An additional caveat of comparing monarch egg densities between regions is the fact that monarch egg density per ramet does not necessarily translate into monarch production. For this, we would also need to consider the total number of milkweed over which this density is distributed. It is therefore imperative to note that the comparison of the abundances between this study and Stenoien et al. [51] should not be taken as evidence of greater monarch production in our area. As such, a larger data set from West Texas that is taken over a greater temporal scale and consistent with monitoring of other regions is necessary in order to achieve a more robust comparison. Nevertheless, it is worth considering the increase we observed because Stenoien et al. [51] evaluated data from as early as 1997 when monarch populations were higher, and they noted that monarch egg densities were declining after 2006. Consequently, we would expect lower egg densities associated with reduced populations, and our findings may have been influenced by factors that warrant future investigation, such as crowding due to reduced milkweed numbers or phenological shifts.

\section{Conclusion}

The wide migratory distribution of the monarch butterfly presents many opportunities to facilitate the conservation of this iconic species. Unfortunately, many areas, like West Texas, may have the potential to benefit monarch conservation that is undermined by a limited knowledge of local milkweed abundance and monarch utilization. While monarch research and protection initiatives are steadily increasing, many of these efforts are still centered on summer breeding areas in the Midwest because the Midwest has among the largest numbers of milkweed, making it a primary source of monarch production [40]. Indeed, we do not argue the significance of the Midwest in terms of monarch conservation. Rather, we emphasize the need to continue expanding conservation efforts outside such prominent regions in pursuit of a more comprehensive approach. This approach would allow the mobilization of resources across a greater base, resulting in more widespread and effective outcomes for monarch conservation, while potentially identifying new priorities in monarch conservation that may arise in our ever-changing world. As such, we hope that this work helps to encourage research and conservation across the entirety of the monarch's migratory range.

\section{Methods \\ Study area}

Monarchs and milkweed were monitored on private ranches in Stonewall County and Fisher County, Texas from September 14th to November 9th, 2018. Both ranches are at the western extent of the monarch migratory corridor and consist of semi-arid rangeland typical of West Texas. The predominant vegetation in this area includes juniper (Juniperus pinchotti), honey mesquite (Prosopis glandulosa), lotebrush (Ziziphus obtusifolia), prickly pear (Opuntia spp.), and silver bluestem (Bothriochloa saccharoides), with a further description of the region provided by Rollins [47]. West Texas hosts a number of milkweed species, including antelope horn milkweed (Asclepias asperula), broad leaf milkweed ( $A$. latifolia), and zizotes milkweed (A. oenotheroides) [50], which provide breeding habitat for monarchs. Additionally, nectar plants in Texas are considered to be a crucial 
(See figure on next page.)

Fig. 5 Map of survey locations. Map depicting the location of the survey counties with respect to their location in Texas (top left). The relative sizes and locations of the Stonewall County survey sites are displayed at the top right and Fisher County site locations and relative sizes are bottom left. Milkweed were only surveyed along the $50 \mathrm{~m} \times 4 \mathrm{~m}$ transect in Fisher 1 due to the immense size of the plot. This figure was created by the authors using ArcMap version 10.8 (https://desktop.arcgis.com/en/arcmap/)

source of lipids for overwintering monarchs [8], and several species of fall blooming wildflowers, including sunflowers (Helianthus spp.), cowpen daisy (Verbesina encelioides), and Illinois bundleflower (Desmanthus illinoensis), occur in our study area [47].

\section{Surveys}

Surveys of monarchs were based on methods utilized by the Monarch Larva Monitoring Project [28]. Monitoring was conducted every 5-10 days at 3 sites per ranch, apart from the final survey which was separated from the previous session by an 11 day interval due to a logistical constraint. The term site(s) will hereafter refer to the 6 survey locations (Fisher 1-3 and Stonewall 1-3). Sites consisted predominantly of indigenous broadleaf milkweed patches and were separated by at least $1 \mathrm{~km}$, except for 2 sites in Fisher County which only had an $30 \mathrm{~m}$ separation and 1 site in Stonewall County which also contained another species of milkweed, zizotes (Fig. 5). All milkweed at each site were surveyed and the species of milkweed, condition of plants (budding, dehiscent, flowering, with seedpod, senescing, and/or vegetative), number of ramets (individual stems denoted by a separation of earth between them), number of monarch and queen butterfly eggs, number and stage of monarch larva, and number and stage of queen butterfly larvae were recorded. At one site in Fisher County, there were more plants than could be feasibly surveyed; therefore, a line transect method was used [15] with all milkweed within a $50 \mathrm{~m} \times 4 \mathrm{~m}$ plot being surveyed as a representative sample for the local milkweed population (Fig. 5).

It should be noted that for Stonewall 1 on September 14th the number of ramets of some milkweed were not recorded if there were no eggs or larvae present, but the presence of those milkweed were noted. To maintain a larger sample size, the ramets that were not recorded were substituted with the average ramets calculated using the complete records from that date and site. We are confident that this is representative of the ramets considering $>90 \%$ of the milkweed at that time and site had only one ramet. Using this substitution, we calculated an overall density of $\sim 0.78$ monarch eggs per milkweed ramet for September 14th. Alternatively, we excluded the site with incomplete ramet data and this produced an overall density of $\sim 0.93$ monarch eggs per milkweed ramet. To provide the most representative estimate of monarch egg density for our study area, we chose to use the smaller value achieved by supplementing the data with averages rather than excluding the site. Given our limited sample size, omitting the data from the entire site would have considerably impacted our results and may have inflated the egg density estimates we used for comparison.

\section{Proportion of eggs based on larva}

Because monarchs are sympatric with queen butterflies in our study areas [35] and the eggs of the 2 species appear identical, we corrected for the number of queen eggs during each survey to prevent over representing monarch abundance. This was done by counting both monarch and queen larvae, which can be distinguished from each other by the number of tentacles present [35], and then dividing the number of monarch larvae by the total larvae to calculate the proportion of monarchs and queens. Confidence intervals for the proportion of monarchs and queens were calculated for each site and sampling period. The total number of eggs observed during each survey was then multiplied by the proportion of monarch and queen larvae from the following survey to produce the corrected number of monarch and queen eggs, respectively. For example, the total number of eggs counted on September 14th was multiplied by the proportion of monarch larvae observed on September 24th, to produce the corrected number of monarch eggs for September 14th. Estimating the number of monarch eggs in this manner was done to account for the time it would take the eggs to develop into larvae, as monarch eggs require $\sim 45$ degree days above a developmental zero of $11.5^{\circ} \mathrm{C}$ to hatch [59], which typically takes $\sim 4$ days under suitable field conditions [33]. The upper and lower confidence intervals of the proportions were also used to give a range of the possible monarch and queen eggs.

\section{Comparisons of abundance}

To illustrate variability between sites and changes in egg and larval distributions over time, stacked bar graphs of all monarch larva stages and estimated monarch eggs for each sampling period and site were generated in RStudio (version 1.2.5033; [45]) using the ggplot2 package [56]. The same was done for queen butterflies. Stacked bar graphs for the condition of all milkweed plants surveyed for each sampling period and site were also generated to illustrate changes in plant abundance and quality 


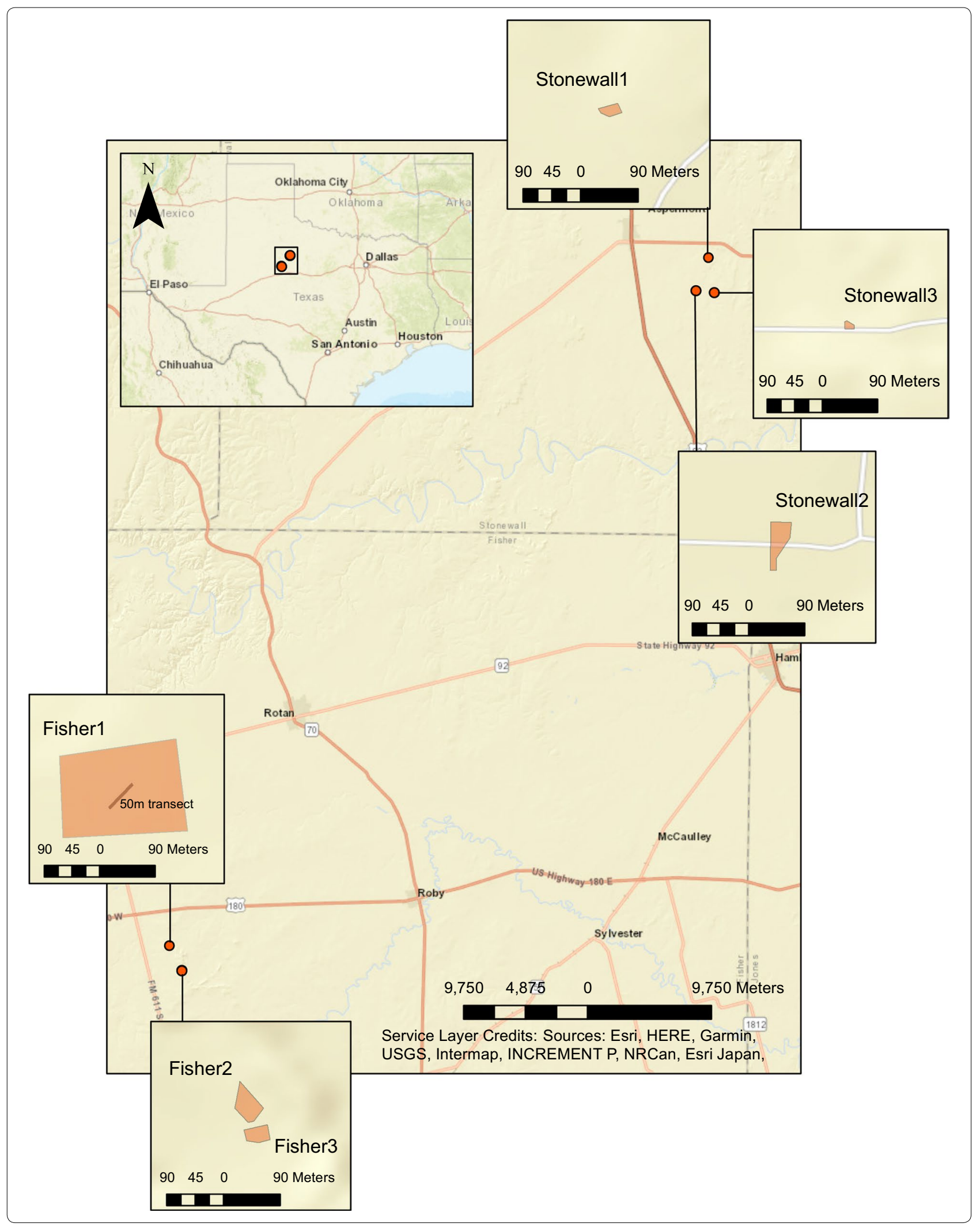


over time. Note that on September 14th the total number of milkweed surveyed was available, but plant condition data for Fisher 1 and Stonewall 1 was incomplete. To best represent the data, these data were included in the bar graphs as not applicable (NA).

Then we used generalized additive mixed models (GAMM; mgcv package; [57]) to determine which factors were important in predicting monarch egg density. Site was used as a random intercept because the same sites were checked at each monitoring session over the course of the study, resulting in repeated samples that were not independent. We hypothesized that Julian day, ramet density (ramets $/ \mathrm{m}^{2}$ ), plot size, and area size were important predictors of monarch egg density, and included these as predictor variables within the GAMM. We used the additive model approach because of the non-linear behavior between monarch egg density across time. Because of the overdispersion of the non-zero density data, the additive model performed better with a negative binomial distribution than a gaussian distribution. We used smoothers for all the data except for the categorical variable (area size). Because of the distinct temporal pattern between the locales (Fisher versus Stonewall), we applied the smoothers for Julian date at the county level. We compared all possible combinations of the predictor variables, which resulted in 15 GAMMs (Table 4). We then calculated Akaike Information Criterion (AIC), corrected AIC $\left(\mathrm{AIC}_{\mathrm{c}}\right)$, Akaike weights $\left(w_{\mathrm{j}}\right)$, and evidence ratio $\left(E_{i}\right)$ to select the best model [11].

The AIC is calculated from the maximum likelihood estimate of the model and the number of $k$ fitted parameters. The equation for AIC is as follows (1):

$$
A I C=-2 \operatorname{In}(L)+2 k
$$

We then corrected AIC because of the number of observations relative to the number of fitted parameters. Where AIC and $k$ are as before (1), and $n$ is the sample size. The equation for $\mathrm{AIC}_{\mathrm{c}}$ is as follows (2):

$$
A I C_{c}=A I C+\frac{2 k(k+1)}{n-k-1}
$$

We calculated Akaike weights for each model $\left(w_{\mathrm{j}}\right)$ from the difference in $\mathrm{AIC}_{\mathrm{c}}$ values between the best model (i.e., with lowest $\mathrm{AIC}_{\mathrm{c}}$ ) and all other models in the candidate set $(\Delta i)$. Where $N$ is the total number of candidate models. The $w_{\mathrm{i}}$ have values ranging between 0 and 1 and can be interpreted as the probability that a given model is the model that predicts the data the best of the candidate models considered. The equation for $w_{\mathrm{i}}$ is as follows (3):

$$
w_{i}=\frac{\exp \left(-0.5 \Delta_{i}\right)}{\sum_{n=1}^{N}\left(-0.5 \Delta_{n}\right)}
$$

Lastly, the evidence ratio $\left(E_{\mathrm{i}}\right)$ is a measure of how much more likely the best model (with weight $w_{\text {best }}$ ) is compared to all other models. For example, if the next-best model has $E_{\mathrm{i}}$ of 2 then the first (best) model is twice as likely to be the best approximating model. The evidence ratio can be computed based on the Akaike weights as follows (4):

$$
E_{i}=\frac{w_{\text {best }}}{w_{i}}
$$

In order to provide a broader context of monarch abundance in West Texas, data from all 6 sites were pooled. We calculated the average density of monarch eggs per ramet for each session by dividing the estimated number of monarch eggs by the total number of milkweed ramets surveyed. Maximum average monarch egg density was compared to published data from the northcentral, northeastern, and southcentral US taken from Stenoien et al. [51].

\section{Abbreviations}

AIC: Akaike information criterion; $\mathrm{AIC}_{\mathrm{C}}$ : Corrected akaike information criterion; $E_{i}$ : Evidence ratio; GAMM: Generalized additive mixed model; NA: Not applicable; US: United States; $w_{i}$ : Akaike weights.

\section{Acknowledgements}

We thank those at our study ranches for their hospitality and property access. In particular, we would like to thank Brad and Melissa Ribelin for their enthusiasm and assistance with this project, as well as their unwavering dedication to the conservation of not only monarchs, but all wildlife. We appreciate the advice and field assistance of David Berman, members of the Wildlife Toxicology Laboratory, and those at the Rolling Plains Quail Research Ranch. We would also like to express our gratitude to the reviewers of this manuscript; their insight was instrumental to improving this paper. Finally, we thank BASF for the financial support necessary to make all of this work possible.

\section{Authors' contributions}

$\mathrm{MB}$ and $\mathrm{RK}$ conceived the study. $\mathrm{MB}$ and $\mathrm{CH}$ collected the data presented in the manuscript. NVG, MB, CH, SLM, and BH performed statistical analyses. All authors contributed to the writing and revision of the final manuscript. All authors read and approved the final manuscript.

\section{Funding}

This study was made possible with the financial support of BASF. The funding body did not play any additional role in the design, collection, analysis, data interpretation, and/or writing of this study.

\section{Availability of data and materials}

The datasets used and/or analyzed during the current study are available from the corresponding author on reasonable request.

\section{Ethics approval and consent to participate}

Ethical committee approval was not required for this study as it was conducted in the US where research involving animals is regulated by the Animal Welfare Act of 1966 and overseen by the Institutional Animal Care and Use Committee, which does not require approval for studies involving invertebrates, with the exception of cephalopods. Furthermore, while monarch and 
queen butterflies were observed in this study, these were not interfered with in any way.

\section{Consent for publication}

Not applicable.

\section{Competing interests}

The authors declare that they have no competing interests.

\section{Author details}

1 The Wildlife Toxicology Laboratory, Texas Tech University, Box 43290, Lubbock, TX 79409-3290, USA. ${ }^{2}$ The Department of Biological Sciences, Texas Tech University, Lubbock, TX, USA.

Received: 16 December 2019 Accepted: 3 June 2020

Published online: 12 June 2020

\section{References}

1. Agrawal A. Monarchs and milkweed: A migrating butterfly, a poisonous plant, and their remarkable story of coevolution. Princeton: Princeton University Press; 2017.

2. Altizer SM, Oberhauser KS. Effects of the protozoan parasite Ophryocystis elektroscirrha on the fitness of monarch butterflies (Danaus plexippus). J Invertebr Pathol. 1999;74(1):76-88.

3. Baker AM, Potter DA. Colonization and usage of eight milkweed (Asclepias) species by monarch butterflies and bees in urban garden settings. J Insect Conserv. 2018;22(3-4):405-18.

4. Batalden RV, Oberhauser K, Peterson AT. Ecological niches in sequential generations of eastern North American monarch butterflies (Lepidoptera: Danaidae): the ecology of migration and likely climate change implications. Environ Entomol. 2007;36:1365-73.

5. Borders B, Lee-Mäder E. Milkweeds: a conservation practitioner's guide. Xerces Society for Invertebrate Conservation. 2014 https://xerces.org/ milkweeds-a-conservation-practitioners-guide/ Accessed 17 September 2019.

6. Bradley CA, Altizer S. Parasites hinder monarch butterfly flight: implications for disease spread in migratory hosts. Ecol Lett. 2005;8(3):290-300.

7. Brower LP, Malcolm SB. Animal migrations: endangered phenomena. Am Zool. 1991;31:265-76.

8. Brower LP, Fink LS, Walford P. Fueling the fall migration of the monarch butterfly. Integr Compar Biol. 2006;46(6):1123-42.

9. Brower LP, Taylor OR, Williams EH, Slayback DA, Zubieta RR, Ramirez MI. Decline of monarch butterflies overwintering in Mexico: is the migratory phenomenon at risk? Insect Conserv Diver. 2012;5:95-100.

10. Brym MZ, Henry C, Kendall RJ. Potential significance of fall breeding of the monarch butterfly (Danaus plexippus) in the rolling plains ecoregion of West Texas. Tex J Sci. 2018;70(1):Note 4

11. Burnham KP, Anderson DR. Model selection and multimodel inference: a practical information-theoretic approach. 2nd ed. New York: SpringerVerlag; 2002.

12. Calvert WH, Zuchowski W, Brower LP. The effect of rain, snow and freezing temperatures on overwintering monarch butterflies in Mexico. Biotropica. 1983;15:42-7.

13. Calvert WH. Fire ant predation on monarch larva (Nymphalidae: Danainae) in a central Texas prairie. J Lepid Soc. 1996:50:149-51.

14. Calvert WH, Wagner M. Patterns in the monarch butterfly migration through Texas - 1993 to 1995. In: Hoth J, Merino L, Oberhauser K, Pisanty I, Price S, Wilkinson T, editors. 1997 North American conference on the monarch butterfly. Commission for Environmental Cooperation: Québec; 1999. p. 119-25.

15. Canfield $\mathrm{RH}$. Application of the line interception method in sampling range vegetation. J Forestry. 1941;39:388-94.

16. Dingle H, Zalucki MP, Rochester WA, Armijo-Prewitt T. Distribution of the monarch butterfly, Danaus plexippus (L.)(Lepidoptera: Nymphalidae), in western North America. Biol J Linnean Soc. 2005;85(4):491-500.

17. Fishbein M, Chuba D, Ellison C, Mason-Gamer RJ, Lynch SP. Phylogenetic relationships of Asclepias (Apocynaceae) inferred from non-coding chloroplast DNA sequences. Syst Bot. 2011;36(4):1008-23.
18. Flockhart DT, Wassenaar LI, Martin TG, Hobson KA, Wunder MB, Norris DR. Tracking multi-generational colonization of the breeding grounds by monarch butterflies in eastern North America. P Roy Soc B-Biol Sci. 2013;280(1768):20131087.

19. Flockhart DT, Pichancourt JB, Norris DR, Martin TG. Unravelling the annual cycle in a migratory animal: breeding-season habitat loss drives population declines of monarch butterflies. J Anim Ecol. 2015;84:155-65.

20. Flockhart DT, Brower LP, Ramirez MI, Hobson KA, Wassenaar LI, Altizer S, Norris DR. Regional climate on the breeding grounds predicts variation in the natal origin of monarch butterflies overwintering in Mexico over 38 years. Glob Change Biol. 2017;23:2565-76.

21. Goehring L, Oberhauser KS. Effects of photoperiod, temperature, and host plant age on induction of reproductive diapause and development time in Danaus plexippus. Ecol Entomol. 2002;27:674-85.

22. Grant TJ, Parry HR, Zalucki MP, Bradbury SP. Predicting monarch butterfly (Danaus plexippus) movement and egg-laying with a spatially-explicit agent-based model: the role of monarch perceptual range and spatial memory. Ecol Model. 2018;374:37-50.

23. Hermann SL, Blackledge C, Haan NL, Myers AT, Landis DA. Predators of monarch butterfly eggs and neonate larvae are more diverse than previously recognised. Sci Rep. 2019;9(1):1-9.

24. Journey North Staff. Monarch peak migration maps. Journey North. https ://journeynorth.org/ (2018). Accessed 2 December 2018.

25. Ladner DT, Altizer S. Oviposition preference and larval performance of North American monarch butterflies on four Asclepias species. Entom Exp Appl. 2005;116(1):9-20.

26. Lemoine NP. Climate change may alter breeding ground distributions of eastern migratory monarchs (Danaus plexippus) via range expansion of Asclepias host plants. PLOS ONE. 2015. https://doi.org/10.1371/journ al.pone.0118614.

27. Luna T, Dumroese RK. Monarchs (Danaus plexippus) and milkweeds (Asclepias species) the current situation and methods for propagating milkweeds. Native Plants J. 2013;14:5-16.

28. Oberhauser $\mathrm{K}$, et al. Monarch larva monitoring project. In: Oberhauser K, Batalden R, Howard E, editors. Monarch butterfly monitoring in North America: Overview of initiatives and protocols. Commission for Environmental Cooperation: Québec; 2009. p. 23-5.

29. Malcolm SB. Anthropogenic impacts on mortality and population viability of the monarch butterfly. Annu Rev Entomol. 2018;63:277-302.

30. Malcolm SB, Cockrell BJ, Brower LP. Spring recolonization of eastern North America by the monarch butterfly: successive brood or single sweep migration. In: MalcomIm SB, Salucki MP, editors. Biology and conservation of the monarch butterfly. Los Angeles: Natural History Museum of Los Angeles County; 1993. p. 253-67.

31. Melillo JM, Richmond T, Yohe GW. Climate change impacts in the United States: The third national climate assessment. U.S. Global Change Research Program. 2014 https://nca2014.globalchange.gov/ Accessed 2 December 2018.

32. National Oceanic and Atmospheric Association Staff. National temperature and precipitation maps. National Oceanic and Atmospheric Association. https://www.ncdc.noaa.gov/temp-and-precip/us-maps/ (2018). Accessed 2 December 2018.

33. Oberhauser KS. Overview of monarch breeding biology. In: Oberhauser KS, Solensky MJ, editors. The monarch butterfly: Biology and conservation. Cornell: New York; 2004. p. 3-8.

34. Oberhauser K, Wiederholt R, Diffendorfer JE, Semmens D, Ries L, Thogmartin WE, et al. A trans-national monarch butterfly population model and implications for regional conservation priorities. Ecol Entomol. 2017:42(1):51-60.

35. Opler PA. A field guide to western butterflies. Boston: Houghton Mifflin Harcourt; 1999.

36. Pelton EM, Schultz CB, Jepsen SJ, Black SH, Crone EE. Western monarch population plummets: status, probable causes, and recommended conservation actions. Front Ecol Evol. 2019;7:258.

37. Peñuelas J, Filella I. Phenology feedbacks on climate change. Science. 2009:324(5929):887-8.

38. Pitman GM, Flockhart DT, Norris DR. Patterns and causes of oviposition in monarch butterflies: implications for milkweed restoration. Biol Cons. 2018;217:54-65. 
39. Pleasants JM, Oberhauser KS. Milkweed loss in agricultural fields because of herbicide use: effect on the monarch butterfly population. Insect Conserv Divers. 2013;6:135-44.

40. Pleasants J. Milkweed restoration in the Midwest for monarch butterfly recovery: estimates of milkweeds lost, milkweeds remaining and milkweeds that must be added to increase the monarch population. Insect Conserv Divers. 2017;10:42-53.

41. Pocius VM, Debinski DM, Pleasants JM, Bidne KG, Hellmich RL, Brower LP. Milkweed matters: monarch butterfly (Lepidoptera: Nymphalidae) survival and development on nine Midwestern milkweed species. Environ Entomol. 2017:46(5):1098-105.

42. Pocius VM, Debinski DM, Pleasants JM, Bidne KG, Hellmich RL. Monarch butterflies do not place all of their eggs in one basket: oviposition on nine Midwestern milkweed species. Ecosphere. 2018;9(1):e02064.

43. Pocius VM, Pleasants JM, Debinski DM, Bidne KG, Hellmich RL, Bradbury SP, Blodgett SL. Monarch butterflies show differential utilization of nine Midwestern milkweed species. Front Ecol Evol. 2018. https://doi. org/10.3389/fevo.2018.00169.

44. Quinn M. Texas monarch watch. Texas Monarch Watch. http://texasento. net/dplex.htm (2018). Accessed 18 September 2019.

45. RStudio Team. RStudio: Integrated Development for R. RStudio, Inc., Boston, MA URL http://www.rstudio.com/ (2019). Accessed 9 February 2020.

46. Robinson RA, Crick HQ, Learmonth JA, Maclean IM, Thomas CD, et al. Travelling through a warming world: climate change and migratory species. Endanger Species Res. 2009;7:87-99.

47. Rollins D. Quails on the Rolling Plains. In: Brennan L, editor. Texas quails: Ecology and management, Texas A\&M University Press, Texas; 2007. p. 117-141.

48. Schultz CB, Brown LM, Pelton E, Crone EE. Citizen science monitoring demonstrates dramatic declines of monarch butterflies in western North America. Biol Conserv. 2017:214:343-6.

49. Semmens BX, Semmens DJ, Thogmartin WE, Wiederholt R, López-Hoffman L, Diffendorfer JE, et al. Quasi-extinction risk and population targets for the Eastern, migratory population of monarch butterflies (Danaus plexippus). Sci Rep. 2016;6(1):1-7.

50. Singhurst J, Hutchins B, Holmes WC. Identification of milkweeds in Texas. Texas Parks and Wildlife Department. 2015. https://tpwd.texas.gov/publi cations/pwdpubs/media/pwd_rp_w7000_1803.pdf. Accessed 2 Dec 2018.

51. Stenoien C, Nail KR, Oberhauser KS. Habitat productivity and temporal patterns of monarch butterfly egg densities in the eastern United States. Ann Entomol Soc Am. 2015:108:670-9.
52. Stenoien C, Nail KR, Zalucki JM, Parry H, Oberhauser KS, Zalucki MP. Monarchs in decline: a collateral landscape-level effect of modern agriculture. Insect Sci. 2018;25(4):528-41.

53. Thogmartin WE, LópezHoffman L, Rohweder J, Diffendorfer J, Drum R, et al. Restoring monarch butterfly habitat in the Midwestern US:'all hands on deck'. Environ Res Lett. 2017;12:5.

54. Urquhart FA, Urquhart NR. Autumnal migration routes of the eastern population of the monarch butterfly (Danaus p. plexippus L.; Danaidae; Lepidoptera) in North America to the overwintering site in the Neovolcanic Plateau of Mexico. Can J Zool. 1978;56:1759-64.

55. Wassenaar LI, Hobson KA. Natal origins of migratory monarch butterflies at wintering colonies in Mexico: new isotopic evidence. Proc Natl Acad Sci. 1998:95:15436-9.

56. Wickham H. ggplot2: Elegant graphics for data analysis. New York: Springer-Verlag; 2016.

57. Wood SN. Fast stable restricted maximum likelihood and marginal likelihood estimation of semiparametric generalized linear models. J R Stat Soc B. 2011;73:3-36.

58. Woodson RE. The North American species of Asclepias L. Ann Missouri Bot Gard. 1954:41(1):1-211.

59. Zalucki MP. Temperature and rate of development. Aust J Entomol. 1982;21(4):241-6.

60. Zalucki MP, Malcolm SB, Paine TD, Hanlon CC, Brower LP, Clarke AR. It's the first bites that count: survival of first-instar monarchs on milkweeds. Austral Ecol. 2001;26(5):547-55.

61. Zalucki MP, Rochester WA, Oberhauser K, Solensky M. Spatial and temporal population dynamics of monarchs down-under: lessons for North America. In: Oberhauser KS, Solensky MJ, editors. The monarch butterfly: Biology and conservation. New York: Cornell; 2004. p. 219-28.

62. Zalucki MP, Parry HR, Zalucki JM. Movement and egg laying in monarchs: to move or not to move, that is the equation. Austral Ecol. 2016;41(2):154-67.

\section{Publisher's Note}

Springer Nature remains neutral with regard to jurisdictional claims in published maps and institutional affiliations.
Ready to submit your research? Choose BMC and benefit from:

- fast, convenient online submission

- thorough peer review by experienced researchers in your field

- rapid publication on acceptance

- support for research data, including large and complex data types

- gold Open Access which fosters wider collaboration and increased citations

- maximum visibility for your research: over $100 \mathrm{M}$ website views per year

At BMC, research is always in progress.

Learn more biomedcentral.com/submissions 